\title{
Surface modification of polycarbonate (bisphenol A) by low pressure if plasma
}

\author{
Deepak P Subedi $* \dagger$, Lenka Zajickovał, Vilma Bursikovał and J an J ancał \\ $\dagger$ Department of Physics, Kathmandu University, Dhulikhel, Kavre, Nepal \\ \$ Department of Physical Electronics, Masaryk University, Kotlarska 2,61137, Brno, TheCzech Republic \\ *Towhom correspondenceshould beaddressed.E-mail:deepaksubedi2001@yahoo.com
}

Effects of low pressure radio frequency (rf) plasma treatment on the surface properties of polycarbonate are presented in this paper. Results obtained from the surface energy measurement after different conditions of treatment are compared. After treatment the surface free energy increased from the original value of $35 \mathrm{~mJ} / \mathrm{m}^{2}$ to $63-74 \mathrm{~mJ} / \mathrm{m}^{2}$. X-ray photoelectron spectroscopy measurements showed an increase in oxygen to carbon ratio after the treatment indicating an increase of oxygen-containing functional groups on the polycarbonate surface. A study of the stability of the modified surface property has been made on the basis of surface free energy. To study the improvement of adhesion between the polycarbonate and thin coatings, organosilicon thin films were deposited on the untreated and plasma treated polycarbonate. The adhesion of film to substrate was quantitatively analysed by 'cross-hatch peel test'.

Key words: Polycarbonate, surface modification, if plasma, ageing, surface energy

Him J Sci 1(2): 115-118

URL: www.himjsci.com/issue2/ polycarbonate
Received: 27 Apr 2003

Accepted after revision: 25 June 2003

\section{Introduction}

Polymershavebeen applied successfullyin fieldssuch asadhesion, biomaterials, protective coatings, friction and wear-resistant composites, microelectronic devices and thin film technology. Polymeric materials have been able to replace traditional engineering materials like metals and glass because of their high strength to weight ratio, resistance to corrosion, possibility of recycling and their relatively low cost. However, the low surface energy of polymers and resulting poor adhesion of additional coatings havealso created numerousimportant technical challenges which haveto beovercomeby manufacturers (Michael etal. 1999). Polycarbonates (PCs) aresynthetic polymers with a very widefield of applications due to their excellent breakage resistance, good transparency, low inflammability and good workability.

In recent years, polycarbonate has become a very attractive business article. The world production of PC increases every year by $8-10 \%$ and nowadays it is more than 1.35 million tonnes/year (Mapleston 1999). The most important types are the PCs based on bisphenol A (business labels Diflon ${ }^{\circledR}$, Macrolon $\AA$, Lexan ${ }^{\circledR}$, and so on). PCscan beused for plastic vesselsand machine parts; optical grades can be used for compact discs (CDs, CDROMs and DVDs), optical fibres, etc. But the low hardness, low scratch resistance and degradation by UV radiation require modification of surface properties by means of additional coating.

Therefore, in many applications (e.g., in industry, technology, biology and medicine) it is necessary to change or improve some of the surface properties of the polymers without altering the bulk properties. Several techniques have been developed to modify the polymer surfaces for improved adhesion, wettability, printability and other technologically important characteristics. The common methods of surface modification includemechanical or chemical treatment; and exposureto flames, photons, ion beams, and other types of radiation (Pasco and Everest 1978). Mechanical treatment alone has limited effectiveness, and chemical treatments with solvents, oxidants such as chromates and permanganates, strong acids or bases, and sodium-liquid ammoniatreatmentsfor fluoropolymersarebecomingincreasingly unacceptable because of environmental and safety considerations. Furthermore, wet chemical treatments tend to entail inherent problems of uniformityand reproduci bility. Amongall themethods of modifying polymer surfacesto improvewettability and adhesion, low pressure plasma treatment has proved to be one of the most effective, ensuringuniformity, as well as being non-polluting.

In general, the surface modification techniques can be divided into threecategories: (i) cleaningand etching by removal of material from thesurface; (ii) surfacereactionsproducingfunctional groupsand cross linking (theseentail littleor no removal or addition of material); and (iii) deposition of thin filmson thesurface(Yasuda et al. 1990, d'Agostino et al. 1990). An important objective of any such treatment isto removeloosely bonded surfacecontamination, thus providing intimate contact between interacting materials on the molecular scale.

This paper discusses the surface modification of PCs utilisinga low pressurerfglow dischargeproduced in argon, oxygen and ammonia gases. However, detailed study of the modified surface has been undertaken after argon and oxygen plasma treatment only. The modified surface has been characterised by measuringthecontactangles and calculatingthesurfacefreeenergy. Thechanges in chemical composition havebeen studied by X-ray photoelectron spectroscopy. The results of adhesion test are also presented.

\section{Materials and methods}

Plasma treatment and film deposition

The major part of the research work consists of plasma treatment and film deposition performed at the plasma chemical laboratory of Masaryk University, Czech Republic. Plasma treatments were carried out in rf capacitively coupled glow discharge. Thebisphenol 
A PC samples of sizes 50 by $60 \mathrm{~mm}^{2}$ were cleaned in isopropyl alcohol and dried before inserting into the reactor. The samples were placed on the powered bottom electrode, which was capacitively coupled to the rf generator PG 501 working at the frequency of $13.56 \mathrm{MHz}$. The effect of treatment timeand if power on the wettability of PC was investigated. The rf power was varied from 100 to $400 \mathrm{~W}$, and the DC negative self bias voltage varied from -10 to $-270 \mathrm{~V}$ depending on the if power and the pressure inside the reactor. The gas flow was controlled by electronic massflow controller. All the treatments were carried out in flow regime. The reactor chamber was pumped by a diffusion pump backed by a rotary pump.

The $\mathrm{SiO}_{2}$ films were deposited from the hexamethyIdisiloxane/ oxygen $\left(\mathrm{HMDSO} / \mathrm{O}_{2}\right.$ ) feeds 4 hours after thetreatment in argon discharge $\left(Q_{A r}=5.7 \mathrm{sccm}, p=1.5 \mathrm{~Pa}, \mathrm{P}=100 \mathrm{~W}, \mathrm{U}_{\text {bias }}=-35 \mathrm{~V}\right.$, $\mathrm{t}=5 \mathrm{~min}$ ). The gases were fed into the reactor through the showerhead electrodeto ensure uniform deposition. The distance between the electrodes was $55 \mathrm{~mm}$. For film deposition, $4 \mathrm{sccm}$ of HMDSO was diluted with two different oxygen flow rates, namely $45 \mathrm{sccm}$ and $10 \mathrm{sccm}$. Therf powers were 100 and $400 \mathrm{~W}$ respectively.

TABLE 1. Surface free energy and its polar and dispersion components of water and glycerine used to determine the surface energy of PC

\begin{tabular}{llll}
\hline Liquid & $\begin{array}{l}\text { Total surface } \\
\text { energy } \\
\left(\mathbf{m} \mathbf{j} / \mathbf{m}^{\mathbf{2}}\right)\end{array}$ & $\begin{array}{l}\text { Polar } \\
\text { component } \\
\left(\mathbf{m} \mathbf{j} / \mathbf{m}^{\mathbf{2}}\right)\end{array}$ & $\begin{array}{l}\text { Dispersion } \\
\text { component } \\
\left(\mathbf{m} \mathbf{m} / \mathbf{m}^{2}\right)\end{array}$ \\
\hline Water & 72.8 & 51 & 21.8 \\
\hline Glycerine & 63.4 & 29.7 & 33.6 \\
\hline
\end{tabular}

Source: Correia et al. 1997

TABLE 2. Atomic concentration of carbon, oxygen and nitrogen measured by XPS for untreated and plasma treated polycarbonate. Plasma treatments were performed for $5 \mathrm{~min}$ at a pressure of $1.5 \mathrm{~Pa}$ and gas flow rate $5.7 \mathrm{sccm}$

\begin{tabular}{llllll}
\hline Gas & Power(W) & \multicolumn{5}{c}{ Atomicconcentration (\%) } \\
\cline { 3 - 6 } & & $\mathbf{C}$ & $\mathbf{O}$ & $\mathbf{S}$ & $\mathbf{N}$ \\
\hline Untreated & - & 84.3 & 15.7 & 0 & 0 \\
\hline $\mathrm{Ar}$ & 100 & 76.4 & 20.3 & 0.4 & 2.2 \\
\hline $\mathrm{O}_{2}$ & 100 & 74.0 & 24 & 0.4 & 1.7 \\
\hline
\end{tabular}

TABLE 3. Results of adhesion measurements of silica films deposited on PC after an argon plasma treatment carried out at different rf powers and treatment times

\begin{tabular}{lllll}
\hline Gas & $\begin{array}{l}\text { Power } \\
\text { (W) }\end{array}$ & $\begin{array}{l}\text { Treatment } \\
\text { time } \\
\text { (min) }\end{array}$ & $\begin{array}{l}\text { Film } \\
\text { thickness } \\
\text { (nm) }\end{array}$ & $\begin{array}{l}\text { Adhesion } \\
\text { (\%) }\end{array}$ \\
\hline Untreated & - & - & 490 & 10 \\
\hline $\mathrm{Ar}$ & 100 & 5 & 459 & 90 \\
\hline $\mathrm{Ar}$ & 400 & 5 & 545 & 96 \\
\hline $\mathrm{Ar}$ & 100 & 10 & 472 & 94 \\
\hline $\mathrm{Ar}$ & 400 & 10 & 523 & 99 \\
\hline
\end{tabular}

Surface characterisation

Over the years a large number of techniques have been developed to probe the different aspects of the physics and chemistry of surfaces; however, only a few have found wideapplication in basic surfacescienceand applied surfaceanalysis. Amongthesemethods, X-ray photoelectron spectroscopy (XPS) and Fourier transform infrared spectroscopy are used to study the surface chemical composition. Similarly, scanning electron microscopy (SEM) and atomic force microscopy (AFM) are used to investigate the surface morphology of the material at the atomic scale. These methods require relatively expensive equipments, skilled technicians and quite sophisticated techniques to interpret the data. A good understanding of thesurface properties of a solid may be obtained relatively inexpensively from the measurement of the surface free energy. Therefore contact angle measurement has been used in the study of surface free energy, wettability and adhesion of low surface energy materials. The surface free energy of a solid is an important parameter, playing a vital role in the phenomena that occur at solid-liquid and solid-gas interfaces. Hence, knowledge of this parameter is useful in studies of adsorption and wettability processeswhich playimportant rolein manyindustrial applications of the material (Zimon 1974, Leja 1982). Measurement of contact angle of liquid with thesolid surface permits a rapid and qualitative evaluation of surface freeenergy of polymers. In the present paper, analysis of the surface free energy of PCs has been made on the basis of dispersive and non-dispersive components. Surface free energy $\left(\gamma_{s}\right)$ and itspolar $\left(\gamma_{s}^{p}\right)$ and dispersion $\left(\gamma_{s}^{d}\right)$ components of the sample were determined from two sets of contact angles (water and glycerine) according to Owens-Wendt-Kaelble equation (OwensandWendt 1969).

$$
\gamma_{l}(1+\cos \theta)=2\left[\gamma_{l}{ }^{d} \gamma_{s}{ }^{d}\right]^{\frac{1}{2}}+2\left[\gamma_{l}{ }^{p} \gamma_{s}{ }^{p}\right]^{\frac{1}{2}}
$$

where, $\gamma_{1}, \gamma_{1}^{p}$ and $\gamma_{1}^{d}$ are the total surface free energy, the polar component and the dispersion component of the surface free energy of theliquid, respectively. The values of the surface free energies of thetest liquids obtained from theliteraturearegiven in Table 1

Thechangesin thechemical composition of thesamples after the plasma treatments wereanalysed by XPS measurements. The measurements were carried out on an ultra-high-vacuum (lower than $10^{-8} \mathrm{~mm} \mathrm{Hg}$ ) surface analytical system equipped with Omicron EA 125 hemispherical analyser working in multi-channel detection regime. The analyser was operated in the retarding field mode using pass energy of $20 \mathrm{eV}$. M gK $\alpha$ was used for excitation. The electron take-off angle was $90^{\circ}$ and the analysed area $6 \mathrm{~mm}$ in diameter. Standard fitting procedure was used to determine the corelevel-peak position and spectral intensities. Thecharging was evaluated and corrected after the fitting of the Cls signal from the position of $\mathrm{C}-\mathrm{H}$ peak, which is characterised by binding energy of $284.6 \pm 0.2 \mathrm{eV}$.

The improvement made by the argon plasma treatment in the adhesive property of PC to thin coating of silica was studied using the cross-hatch peel test method. $\mathrm{SiO}_{2}$ films of about half mmthicknessweredeposited by plasmaenhanced chemical vapour deposition (PECVD) on the untreated and plasma treated PC. The deposited filmswerecut into 3842.5 by $2.5 \mathrm{~mm}^{2}$; adhesivetape(3M No. 369) wasthen applied to thefilmand pulled swiftly. Thenumbers of the squares adhering to the $\mathrm{PC}$ was counted and the ratio of the adhering film area to the total area of the film under the applied tape was determined. The percentage adhesion of the films after different conditions of argon plasma pre-treatment was determined. 


\section{Results and discussion}

Surface free energy measurement

The values of surface free energy and its components before and after the treatment in argon, oxygen and ammonia plasmas are compared in Figure 1. The surface energy corresponds to the contact anglesmeasured within 10 min of theplasmatreatment. It shows that all three types of treatment can produce significant increase in the surface free energy. The treatment carried out in argon and oxygen plasma resulted a higher value of total surface energy compared to ammonia plasma. Argon plasma treatment produces purely physical surface modification; no new functional groups are incorporated on the polymer surface. The direct and radiative energy transfer processes causethesurfacemodification in all typesof inert gasplasma treatments. The directenergy transfer corresponds to the ion bombardment of the surface, which is particularly important in the case of the PC specimens placed on thedc- biased capacitively-coupled rfelectrode. Another important factor for the modification mechanism is the UV (VUV) radiation emitted by the plasma (Chan et al. 1996). The exposure of the sampleto theargon dischargeissufficient to break chemical bonds $(\mathrm{C}-\mathrm{C}, \mathrm{C}-\mathrm{H})$, leaving free radicals at or near the surface. These radicals can react only with other surface radicals or by chaintransfer reactions. If the polymer chain is flexible, or if the radicals can migratealongit, then recombination, unsaturation, branching, or cross-linking can occur. Moreover, the plasma removes low molecular weight species or converts them to high molecular weight species by crosslinking reactions. In summation, theargon plasma treatment causes the crosslinking of the PC surface as well as the sputtering of the material.

Unlike argon plasma, the oxygen plasma produces a variety of new functional groupsincluding $\mathrm{C}-\mathrm{O}, \mathrm{C}=\mathrm{O}, \mathrm{O}-\mathrm{C}=\mathrm{O}, \mathrm{C}-\mathrm{O}$ $\mathrm{O}$, that increasepolymer wettability. In general, two processes may occur simultaneously during the oxygen plasma treatment: (i) etching of the polymer surface through the reactions of atomic oxygen with the surface carbon atoms, yielding volatile products, and (ii) the formation of oxygen functional groups at the polymer surface through reactions between the active species from the plasma and the surface atoms. Hence, for oxygen plasma, the reactive oxygen atoms play an important role in the surface modification of the sample.

The mechanism of surface modification in the case of ammonia plasma treatment is somewhat similar to that of oxygen plasma. Ammonia plasma treatment incorporates hydrophilic functional groups such as amine $(\mathrm{N}-\mathrm{H})$, imine $(\mathrm{N}=\mathrm{C})$, nitrile $(\mathrm{N} \equiv \mathrm{C})$ and amide $(\mathrm{N}-\mathrm{C}=\mathrm{O})$ on the surface of PC. Moreover, theadditional oxygen functional groups can be incorporated after the ammonia plasma treatment because free radicals created on the surface react with oxygen when the surface is exposed to the atmosphere (Hudis 1974)

For untreated PC the values of polar and dispersion components of surface free energies are almost the same. But there is a substantial increase in the polar component after all treatments, whereas no any remarkable change in the dispersion component was observed. The ratio of polar component to the total surface free energy is also regarded as the polarity of the material. An important information obtained from the surface energy measurement is that the polar component increases, corresponding to the formation of covalent bonds. The formation of covalent bonds plays an important role in adhesion at the interface.

\section{XPS Analysis}

Further information about the changes induced by argon and oxygen plasma treatment was obtained from the XPS measurements. Theatomic compositions of thePC surface before and after the treatment are compared (Table 2). The treatments produced a decreasein thecarbon concentration on thePC surface. On theother hand theoxygen content increased and a small amount of silicon and nitrogen appeared. The impurity of the silicon is caused by thefact that the reactor was also used for the deposition of silicon oxides. Although, before the PC treatment experiments thereactor wascleaned mechanically as well as in argon and oxygen dischargestherewasprobablystill someresidual silicathatappeared on thePC surface. Thenitrogen impurity found on the sampleafter thetreatment could bethenitrogen incorporated during theplasma treatment as a result of somenitrogen traces in the feed gas as well as after the exposure of the treated surface to the atmosphere.

\section{Adhesion measurement}

The percentage adhesivity of the $\mathrm{SiO}_{2}$ films deposited on PC with and without pre-treatment is presented in Table 3. A significant improvement in the relative adhesivity of the film to substrate is achieved by argon plasma treatment made before deposition of the film. A five-minute argon plasma treatment was sufficient to increase the relative adhesivity from $10 \%$ to as high as $96 \%$. The argon plasma pre-treatments were made with two different rf

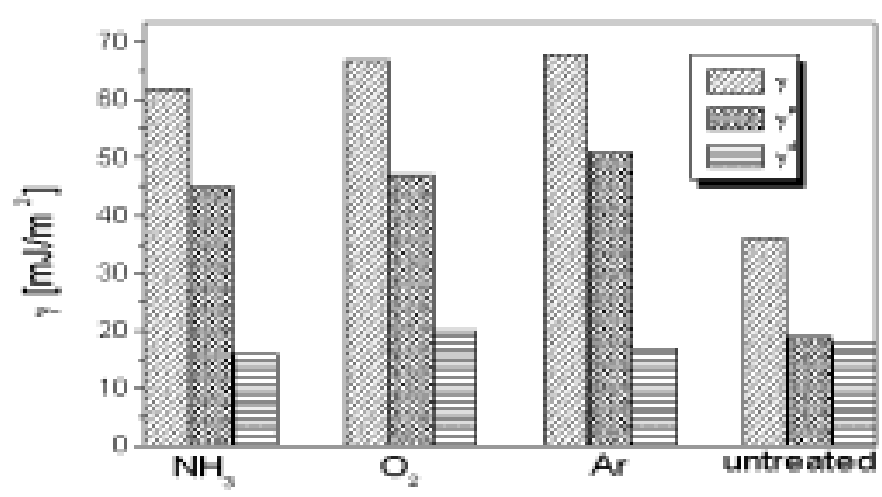

FIGURE1. Comparison of surface free energy and its components before and after the treatment in $\mathrm{Ar}, \mathrm{NH}_{3}$ and $\mathrm{O}_{2}$ discharges. The domain represents the types of the sample. The treatment conditions were $P=$ $100 \mathrm{~W}, \mathrm{Q}=52 \mathrm{sccm}, \mathrm{p}=36.5 \mathrm{~Pa}$, and exposure time $\mathrm{t}=10 \mathrm{~min}$. The bias voltages $U_{\text {bias }}$ were $-20,-25,-30 \mathrm{~V}$ for ammonia, oxygen and argon discharges respectively.

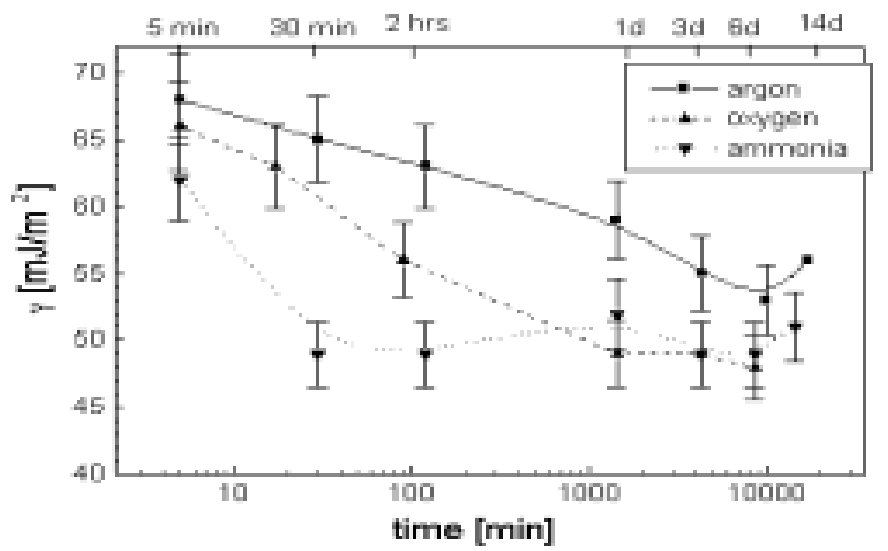

FIGURE 2. Ageing of surface free energy of $P C$ after treatment in $\mathrm{Ar}, \mathrm{NH}_{3}$ and $\mathrm{O}_{2}$ plasmas. The treatment conditions were $\mathrm{P}=100 \mathrm{~W}, \mathrm{U}_{\text {bias }}=-25 \mathrm{~V}$, $\mathrm{Q}=52 \mathrm{sccm}, \mathrm{p}=36.5 \mathrm{~Pa}$. and treatment time $\mathrm{t}=10 \mathrm{~min}$. The bars in the graph correspond to standard deviation. 
powers and treatment time in order to observe the influence of these parameters on the adhesivity. However, the difference in the results for the treatments at different if powers and with different treatment times was within the limit of experimental error.

The adhesion or bondability between polymer surfaces and other materials deposited onto them can often be related to wettability as determined from the contact angle measurements. Plasma treatment can improve adhesion to polymers via surface cleaning, cross-linking, or formation of chemical bonds. The increased adhesivity produced by argon plasma treatment is well supported by our contact angle measurements. From these we observed that argon plasma treatment under the conditions as used before the film deposition produces significant increase in wettability of PC, which can be correlated with the increased adhesivity. A previous study of the adhesivity of $\mathrm{SiO}_{2}$ film to $\mathrm{PC}$ has reported that a Si-O-C bond must be formed in order to produce the strong adhesivity of the film to the substrate. The unsaturated bonds opened by the treatment in argon plasma can help the formation of such bond and hence increase the adhesion.

A scratch test performed on $\mathrm{PC}$ showed that $\mathrm{SiO}_{2}$ films deposited without pre-treatment were almost completely delaminated from the surface, whereas there was negligible delamination of the film deposited on PC after argon plasma pretreatment. The characteristics of thin $\mathrm{SiO}_{2}$ films deposited on PC by PECVD have also been discussed in our previous paper (Zajickova etal. 2001).

Wealso studied the dependenceof thesurfacefreeenergy of the sample on time after treatment. For that purpose, surface energy of PC was measured for several days after the treatment in $\mathrm{Ar}, \mathrm{O}_{2}$ and $\mathrm{NH}_{3}$ plasma by storing the samples in a dust-free environment. The results are shown in Figure 2 . It indicates that themost stablemodification of PC surfacewas produced by argon plasma treatment. On the other hand, ammonia plasma resulted in the least stable modification of the surface.

This effect, commonly known as 'ageing', is important from the point of view of industrial application. Ithas been reported that ageing is dueto (i) thermodynamically driven reorientation of polar species away from the surfaceto the subsurface, (ii) diffusion of mobile additives from the polymer bulk to the surface, and (iii) the reaction of residual free radicals with the ambient (Spell and Christension 1979). Themorestablesurfacefreeenergy after argon plasma treatment is due to the cross-linking effect. The uses of cross-linking process via inert gas plasma treatments to obtain better surfaceproperties are discussed in detail elsewhere(M ichael et al. 1999, Sheu et al. 1992, Vallon et al. 1996). The result clearly indicates the different effects of treatment in inert and reactive plasmas.

\section{Conclusion}

The effects of argon, oxygen and ammonia plasma treatments on PC are discussed in the paper. The result of surface energy measurement and its dependence on time after treatment are summarised. All types of treatmentresulted an appreciableincrease in the wettability of thesample. However, theimproved wettability decreased with time. Results of XPS analysis revealed an increasein $\mathrm{O} / \mathrm{C}$ ratio of the sample after the treatment. The peel tape test showed that a significant improvement in adhesivity of deposited protectivefilm to PC can beachieved by performing atreatment of the sample before the deposition of the film.

\section{References}

Chan C-M, T-M Ko and H Hiraoka. 1996. Polymer surfacemodification by plasmasand photons. SurfaceSci Rep 24(1-2): 1-54

CorreiaNT,JJM Ramos, BJVSaramago andJCG Calado. 1997. Estimation of thesurface tension of a solid:Application to a liquid crystallinepolymer.J Colloid Interface Sci 189(2): 361-9

d'Agostino R, F Cramarossa and F Fracassi. 1990. Plasma polymerization of fluorocarbons. In: d'Agostino R (ed), Plasma deposition, treatment, and etchingof polymers. NewYork: Academic Press. p 95-162

Hudis M. 1974. Techniques and application of plasma chemistry. New York: WileyInterscience. p 113-47

LejaJ. 1982. Surfacechemistry of froth flotation. NewYork: Plenum Press

Mapleston P. 1999. Modern plasticsinternational

Michael RM, L Martinu and JE Klemberg-Sapieha. 1999. In: Mittal KL (ed), Adhesion promotion techniques: Technological applications. New York: Marcel Dekker

OwensDK and RCWendt. 1969. J Appl Polym Sci 13:1741-7

PascolK and JH Everest. 1978. OpticsLaser Technol 10: 71

Sheu MS, ASHoffman and J Feijen. 1992. A glow dischargetreatment to immobilise poly (ethyleneoxide)/ poly (propyleneoxide) surfactants for wettableand nonfauling biomaterials. J Adhesion Sci Technol 9: 995-1009

Spell HL and CP Christension. 1979. Tappi J 6: 77

Vallon S, A Hofrichter, L Guyot, B Drévillon,J EKlemberg-Sapieha, L Martinu etal. 1996. Adhesion mechanisms of silica layers on plasma-treated polymers. Part I. Polycarbonate. J Adhesion Sci Technol 10(12): 1287-313

YasudaHK,YSYeh and SFusselmann. 1990. PureAppl Chem 63: 1689

Zajickova L, V Bursikova, V Perina, A Mackova, D Subedi, J Janca et al. 2001. Plasma modification of polycarbonates. SurfaceCoatings Technol 142-144: 449-54 Zimon AD. 1974. Chem Moscow

\section{Acknowledgements}

Wethank KaterinaVeltruska, Charles University, Czech Republic, for her kind help with theXPSmeasurementand analysis, and Pavel Stahel, MasarykUniversity, for hishelp with contactanglemeasurements. 